\title{
¿HAY LUGar aún PARA OtRo ENFOQUE EN LA ENSEÑANZA DE LENGUAS? UNA RESEÑA DE SCAFFOLDED LANGUAGE EMERGENCE in the Classroom: From Theory to Practice
}

\author{
Norman Darío Gómez-Hernández \\ M. A. Didáctica de la Traducción, \\ Universidad de Antioquia, Colombia. \\ Doctorando, Didáctica de la \\ Traducción, Facultad de Traducción, \\ Lingüística y Estudios Culturales \\ (FTSK), Alemania (Becario Colciencias \\ "Doctorando Exterior 646" \\ 2015-2019). Miembro grupo de \\ investigación en Traducción y Nuevas \\ Tecnologías TNT. \\ In der kleinen Au 2, 76726. \\ Germersheim, Alemania. \\ ngomezhe@students.uni-mainz.de
}

Título: Scaffolded Language Emergence in the Classroom: From Theory to Practice Autores: Donald Kiraly y Sarah Signer Editorial: Frank \& Timme Año de publicación: 2017 Número de páginas: 144 ISBN: 978-3-7329-0259-0
A pesar de que en nuestros días es cada vez más obvia la necesidad de aprender no solo una, sino varias lenguas extranjeras, aún se siguen utilizando enfoques y métodos para su enseñanza que vieron su luz varios siglos atrás. Y, sorprendentemente, en la práctica, estas maneras de enseñar prevalecen en muchos ambientes educativos de Occidente, aunque se quiera mostrar lo contrario. Tal prevalencia, para Kiraly (2017), se debe a que:

[...] los enfoques alternativos al paradigma de la 'información empaquetada' en la enseñanza de las lenguas extranjeras han surgido sin cesar [...] Pero prácticamente todos ellos han sido abandonados finalmente, dejando como victoriosa esa práctica que considero aún como totalmente transmisionista, consistente en el intento de transferir trozos de conocimiento sobre una lengua a sus potenciales aprendices... ${ }^{1}$ (Kiraly, en Kiraly y Signer, 2017, p. 11).

Pero, aunque de algún modo tales enfoques y métodos parecen funcionar, estos demuestran poca efectividad ante las necesidades de nuestro mundo cambiante, quizás por su apego a una epistemología positivista que defiende la existencia de un conocimiento externo a los estudiantes (cf. Rutherford, 1987, p. 209 y Dalke et al., 2007, p. 111, citados en Kiraly, 2017, p. 11) y que es visto como “... un conjunto de hechos que pueden y deben ser transmitidos del profesor (y del libro) a los alumnos" (Meddings y Thornbury, 2009, p. 14).

En un intento por ofrecer una alternativa diferenciadora y mejor fundamentada, los autores de Scaffolded Language Emergence in the Classroom, Don Kiraly y Sarah Signer, describen el enfoque SLE (scaffolded language emergence $)^{2}$ de forma concisa, en este libro de solo 144 páginas. Basados en sus experiencias como creador y promotor del enfoque, el primero, y como analista de una serie de tesis sobre dicho enfoque, la segunda, ellos explican cómo esta propuesta está orientada al apren-

1 Traducción propia, en esta y las citas subsiguientes.

2 Renombrado como Emergencia de las lenguas adicionales, en la versión en español.

DoI: $10.17533 /$ udea.ikala.v24n03a11

Received: 2018-02-28 / Accepted: 2018-10-09 / Published: 2019-09-20 
dizaje de una segunda (tercera, cuarta...) lengua de manera más efectiva, interactiva, colaborativa y auténtica. Sin recurrir a elaborados artilugios lingüísticos, pero conservando la terminología necesaria para la comprensión de la temática, los autores presentan, de manera clara y detallada, esta innovadora propuesta que tiene sus orígenes en una variedad de enfoques humanistas que la preceden y de los que se decanta lo mejor para crear su propia epistemología.

El libro sugiere el SLE como un enfoque postmétodo ante la ineficacia de los llamados 'métodos tradicionales' en diferentes entornos, lo que hace casi obligatoria una revisión y actualización (por no decir, una completa reestructuración) de las metodologías de enseñanza de lenguas extranjeras que siguen métodos instruccionistas:

La premisa clave sostiene que tiene que existir un uso verdadero de actos de comunicación auténticos para que suceda la emergencia de la lengua [...] y no única, o principalmente, un uso de tareas artificiales o totalmente controladas por los autores de los libros de enseñanza o por los profesores. (pp. 17-18)

Este enfoque en particular se orienta a la enseñanza de lenguas para un público mayormente adulto (aunque no necesariamente universitario) sin conocimientos, o con un conocimiento incipiente, de la lengua objeto de estudio. También nos invita a reflexionar sobre la poca efectividad que los métodos tradicionales (centrados en el profesor, y basados en contenidos lexicales y gramaticales) ofrecen a los aprendices adultos de lenguas y con necesidades de aprendizaje específicas, necesidades que no pueden suplirse con la enseñanza centrada en el profesor y la "tiza y tablero", o con sus versiones modernas de computador y proyector (las cuales resultan casi idénticas en cuanto a las opciones de interacción que ofrecen en el aula de lenguas). Este enfoque humanista promueve una enseñanza centrada en la emergencia paulatina del lenguaje en el individuo y en la comunidad lingüística creada en el aula de clase, como producto de una construcción propia y apoyada por el entorno inmediato, con un trabajo conjunto en pro de la creación de la nueva lengua. Tal emergencia se opone a la instrucción tradicional, que conlleva necesariamente un "trasvase" de información, siempre en la dirección, profesor-alumno. A continuación, se presenta una breve mirada a los temas y capítulos desarrollados en el libro:

La obra se divide en dos secciones principales y una corta sección más, a modo de conclusión.

\section{Sección I. Génesis y pilares teóricos del enfoque SLE (escrita por Don Kiraly)}

Después de una introducción, donde el profesor Kiraly critica la prevalencia de un único método de enseñanza de lengua durante siglos, él plantea por qué algunos métodos alternativos a la gramática-traducción han fracasado en su intento por ofrecer otras opciones de enseñanza. En los seis capítulos siguientes, Kiraly se refiere a la génesis y la fundamentación teórica del enfoque SLE y a cómo surge a partir de sus experiencias, de más de tres décadas, en enseñanza de lenguas. Aquí se incluyen conceptos como el constructivismo social y las zonas de desarrollo próximo (ZDP) de Vigotsky; el enfoque estructuro-global audiovisual (SGAv); la respuesta fisica total, y el enfoque natural de Krashen. Igualmente, importantes en este enfoque son la teoría de la complejidad, y el andamiaje o scaffolding, propuesto por Jerome Brunner.

Los dos capítulos iniciales explican cómo surge el enfoque SLE dentro del proyecto de enseñanza delenguas "B1 en 9 meses" creado para iniciar, fomentar y mejorar la emergencia de lenguas adicionales en estudiantes adultos de la Facultad de Traducción, Lingüística y Estudios Culturales (FTSK) de la Universidad Johannes Gutenberg, en Alemania. También se refieren a cómo se ha utilizado para facilitar el aprendizaje de los estudiantes en cursos de 13 lenguas diferentes, llevándolos de un nivel de suficiencia cero a un nivel medio en las respectivas lenguas. Kiraly justifica la necesidad de este enfoque alternativo, que él incluye dentro de la categoría post-método, y aclara que el SLE se basa, entre otros aspectos, en una concepción socioconstructivista y 
en premisas del pensamiento complejo, que ven el lenguaje como fenómeno holístico que surge a partir de actividades autenticadas y de la inclusión de la corporalidad en el aprendizaje.

En los capítulos 3 y 4 se describen los enfoques y métodos en que se inspiró el SLE, principalmente el enfoque humanista para el aprendizaje de las lenguas conocido como SGAV, el enfoque natural, y la respuesta física total. Se explica cómo las actividades de dichas propuestas, centradas en la reinserción de factores físicos, emocionales y sociales como complemento a los aspectos cognitivos, contribuyeron al enfoque. De igual manera, el autor argumenta las diferencias entre el enfoque natural y el paradigma socioconstructivista para la adquisición del lenguaje, dos epistemologías radicalmente diferentes que, sin embargo, se conjugan de alguna manera en el SLE.

El capítulo 5 presenta el concepto de emergencia desde la perspectiva del pensamiento complejo como el segundo principio subyacente del enfoque SLE. Aquí son importantes las entidades anidadas que funcionan como sistemas "autogeneradores (autopoiéticos)", "autorreguladores" y "adaptativos". También se enfatiza la importancia del andamiaje o scaffolding, como una perspectiva pedagógica transformacional, donde se entiende que el conocimiento se desarrolla a través de la interacción iterativa, dinámica y comunicativa, en lugar de la recepción, la práctica repetitiva y la acumulación (p. 48). Fundamental es también la diferenciación entre las potencialidades (affordances) y lo que tradicionalmente se conoce como el input, puesto que las primeras posibilitan una transformación en la comprensión del proceso de aprendizaje como una negociación de significados con los demás, y con el entorno social, material y de experiencias.

El capítulo 6, último de esta primera sección, hace un recuento de las ideas, conceptos, y hallazgos presentados en el libro y busca presentar algunos lineamientos pedagógicos de utilidad para quienes deseen utilizar el SLE en sus actividades de enseñanza, aclarando que estas son solo posibilidades en el extenso universo de opciones que ofrece la complejidad.

\section{Sección II. De la teoría al uso práctico (escrita por Sarah Signer)}

En sus cinco capítulos, la profesora Signer analiza, de manera rigurosa, el contenido de siete tesis de estudiantes de grado y de maestría de la Facultad de Traducción, Lingüística y Estudios Culturales (FTSK). En dichas tesis, los estudiantes plasman los resultados de sus investigaciones y observaciones sobre el desarrollo y la efectividad de los cursos que se han realizado en esa facultad durante los últimos diez años, usando el enfoque SLE. La intención de la profesora Signer es describir el uso práctico del enfoque, analizando anotaciones y citaciones extraídas de las tesis mencionadas. Ella recurre a este procedimiento pues, como aclara, nunca ha dirigido ni participado de un curso con ese enfoque.

No obstante, y a pesar de la subjetividad inherente a un estudio como éste, ella hace un análisis interesante de cómo se reflejan en las tesis los conceptos de las potencialidades, los significantes y la personalización (capítulo 7); cómo los cursos basados en SLE se apartan de la enseñanza tradicional, y cómo enfatizan en el aprendizaje autónomo (capítulo 8); y cómo se refleja la autonomía y la colaboración en los entornos SLE, así como el desempeño de los facilitadores en contextos diferentes a las aulas tradicionales (capítulo 9). En el capítulo 10, se describen las características comunes de un salón de clase con el enfoque SLE. En oposición a un salón de clases convencional, el aula de SLE demanda mayor espacio, y un mobiliario mínimo, para posibilitar el libre movimiento y la interacción dinámica necesaria para la enseñanza con este enfoque. Igualmente se invita al desarrollo de actividades en otros entornos y al aire libre, donde las interacciones sean más auténticas.

En el capítulo 11, la profesora Signer explica cómo el enfoque SLE crea el puente entre el andamiaje inicial y la emergencia básica del lenguaje adicional, gracias a aspectos inherentes a estos cursos, 
como el condicionamiento de comunicarse únicamente en la lengua extranjera desde el inicio de los cursos, el fomento de la corrección constructiva que propenda a la autocorrección, la revisión por pares, o integrada en actividades orientadas a corregir faltas recurrentes, pero de forma inadvertida (corrección proléptica). La preferencia de la fluidez sobre la precisión también es un aspecto destacable de este enfoque: "el énfasis principal debe estar en la habilidad para comunicarse de manera efectiva, no en el uso perfecto, casi nativo del idioma" (p. 120). Este capítulo concluye con ejemplos y citas de cómo la emergencia se refleja en tres aspectos: el incremento de vocabulario no enseñado explícitamente en la clase, el descubrimiento de reglas gramaticales por los mismos estudiantes, y el uso espontáneo de la lengua adicional que hacen los estudiantes por fuera de la clase.

\section{Sección III. Un prólogo... en lugar de una conclusión (escrita por Don Kiraly)}

El libro concluye con un breve capítulo del profesor Kiraly (capítulo 12), donde se hace un recuento de los conceptos básicos del enfoque y se brindan una serie de recomendaciones para el diseño de los cursos SLE. El capítulo final se escribe a modo de invitación a los posibles facilitadores para que consideren este enfoque dentro de sus prácticas de enseñanza de lenguas extranjeras, recordando que éste no se debe entender como un método, sino como un enfoque, es decir, como "un conjunto de suposiciones entretejidas que surgen de manera abductiva” (p. 9). Kiraly es enfático en que el SLE fomenta la flexibilidad en el uso de las actividades para adaptarse a la complejidad de cada situación de aprendizaje, y que cada facilitador deberá adaptar sus cursos a la realidad específica de sus alumnos, ofreciendo el andamiaje necesario y aprovechando al máximo las potencialidades ofrecidas por el entorno, el trabajo colaborativo, la personificación del aprendizaje, y el fomento de la complejidad.

A modo de conclusión, se puede decir que esta obra tiene una importancia innegable, tanto en el campo pedagógico como en el didáctico, por no referirse específicamente a un método o guía de trabajo, sino a un enfoque con grandes posibilidades de éxito, como se ha demostrado empíricamente, aunque en un contexto reducido hasta el momento (la Facultad de Traducción, Lingüística y Estudios Culturales, FTSK). Lo anterior debido a que el libro aborda una temática de amplia trascendencia y de aplicación general, como es la enseñanza de lenguas extranjeras para el público adulto, sin restringirse a un idioma en particular. Igualmente, la división de la obra en una sección teórica y otra sobre la aplicación práctica permite comprender la funcionalidad del enfoque de manera fácil e interesante.

La obra demuestra convincentemente la manera en que el enfoque SLE conglomera conceptos de varios enfoques humanistas para el aprendizaje de lenguas en una sola propuesta epistemológica — tales como la personificación del lenguaje, el andamiaje, las potencialidades, las actividades auténticas ( $\mathrm{y}$ autenticadas), la emergencia, y la inclusión de la complejidad. Además, explica cómo la flexibilidad y versatilidad, necesarias para adaptarse al contexto complejo del aula, permiten que cada facilitador adapte sus cursos a la realidad específica de sus alumnos ofreciendo el andamiaje necesario y aprovechando al máximo las potencialidades ofrecidas por el entorno.

Se puede observar en la obra que el enfoque presentado puede, inicialmente, despertar cierto rechazo por parte de los profesores-facilitadores, e incluso de los mismos estudiantes. Tal como lo observa la profesora Signer, la mayoría de los facilitadores (en los cursos de la FTSK) provenían de entornos centrados en el profesor lo que, lógicamente, produce:

\footnotetext{
un cierto grado de escepticismo hacia el enfoque propuesto, lo que no es muy sorprendente debido a que todos los estudiantes-facilitadores habían tenido amplia experiencia estudiando varias lenguas extranjeras basadas en métodos convencionales. (Signer, en Kiraly y Signer, 2017 , p. 100)
}

Una reacción similar puede ocurrir también con algunos estudiantes: 
Años de enseñanza tradicional centrada en el profesor, en entornos educativos institucionalizados, tienen necesariamente algún impacto, sin importar cuán abiertos y flexibles sean los estudiantes. (Signer, en Kiraly y Signer, 2017, p. 90).

Ciertamente, la adopción del enfoque requiere de un cambio de mentalidad respecto a la enseñanza y el aprendizaje de lenguas, pues no resulta fácil romper los moldes forjados durante una larga tradición educativa. Sin embargo, Kiraly llama la atención respecto a que:

no puede haber una única, mejor manera de enseñar lenguas extranjeras; solo puede haber maneras más o menos útiles, en términos pragmáticos, para un momento dado o inclusive para cada grupo específico de aprendices. (Kiraly, en Kiraly y Signer 2017, p. 134)

Tras usar esta propuesta didáctica activamente en mis propias clases de lenguas por más de tres años, he podido constatar su validez y efectividad en el contexto universitario alemán, y con alumnos de lenguas altamente comprometidos. Igualmente, mi experiencia en la enseñanza de lenguas extranjeras con universitarios colombianos me hace ser positivo respecto a su viabilidad y efectividad en el contexto latinoamericano. Por tal razón, el profesor Kiraly y yo hemos publicado una segunda versión de esta obra bajo el título SLE: Un enfoque didáctico para fomentar la emergencia de lenguas adicionales (Kiraly y Gómez, 2019), dirigida y adaptada al público de habla hispana. Si quienes han aprendido una o más lenguas extranjeras con los métodos convencionales aún se preguntan "¿para qué cambiar lo que ha funcionado hasta ahora, si pudimos aprender de la forma tradicional?", seguramente podrán encontrar respuestas interesantes a tal interrogante al leer este pequeño libro o su versión en español. Pues en él se demuestra que siempre puede haber espacio para enfoques 'alternativos' para la enseñanza de las lenguas, más aún cuando estos también fomentan el desarrollo de la autonomía, el trabajo colaborativo y otros aspectos humanistas que contribuyen a la formación integral de los estudiantes.

\section{Referencias}

Kiraly, D. y Gómez, N. (2019). SLE: Un enfoque didáctico para fomentar la emergencia de lenguas adicionales. Munich: AVM.

Meddings, L. y Thornbury, S. (2009). Teaching unplugged: Dogme in English language teaching. Surrey: Delta Publishing.

How to reference this article: Gómez-Hernández, Norman Darío (2019). ¿Hay lugar aún para otro enfoque en la enseñanza de lenguas? una reseña de Scaffolded Language Emergence in the Classroom: From Theory to Practice. Íkala, Revista de Lenguaje y Cultura, 24(3), 653-657. Dor: 10.17533/udea. ikala.v24n03a11 